\title{
Automated External Defibrillator Availability and CPR Training among Police Officers in the Campania Region: a Comparison of conventional and Peer-Led Trainings
}

\section{Maurizio Santomauro ${ }^{1 *}$, Carla Riganti ${ }^{2}$, Ciro Aiello ${ }^{3}$, Mario Alberto Santomauro ${ }^{1}$, Raffaele Giordano ${ }^{1}$, Francesco Elia $^{4}$, Riccardo Franco ${ }^{4}$, Mario Petretta ${ }^{4}$ and Domenico Bonaduce ${ }^{4}$}

\author{
${ }^{1}$ Department of Cardiovascular Emergency, Internal Medicine and Geriatric, Medical School, Federico II University of Naples, Italy \\ ${ }^{2}$ General Direction, 2nd Medical School, Federico II University of Naples, Italy \\ ${ }^{3}$ Clinic Center, Police Department, Naples, Italy \\ ${ }^{4}$ Department of Translational Medical Sciences, Federico II University Naples, Italy
}

*Corresponding Author: Maurizio Santomauro, Department of Cardiovascular Emergency, Internal Medicine, Geriatric, Medical School, Federico II University, Italy.

Received: May 20, 2019; Published: July 02, 2019

DOI: $10.31080 /$ ASMS.2019.03.0335

\begin{abstract}
Theory: Survival rate after cardiac arrest strongly depends on the delay occurring from the beginning of Basic Life Support and Defibrillation (BLSD) and then Advanced Life Support (ALS). Providing more bystanders as first rescuer could improve survival after cardiac arrest on the territory.

Hypothesis: In this study we wanted to compare a peer to peer BLSD training to a professional BLSD training for police officers in the Campania region. Furthermore we matched in these two different trainings the skills maintained after one year.

Methods: In this retrospective study we evaluated the feasibility and efficacy of a peer to peer BLSD teaching compared to a professional teaching in the police officers. From 2013 to 2018700 police officers (Group A) were trained in peer to peer while 620 police officers (Group B) were trained with traditional course.

Results: The results demonstrated that check for responsiveness percentage was 68.5\% in Group A and 70.4\% in the Group B; the calls to Emergency System 118 percentage was $88.5 \%$ in the Group A and $90.9 \%$ in the Group B; open the airway and giving breaths percentage was 52\% in the Group A and 52,3\% in the Group B; chest compressions percentage was 83.9\% in the Group A and 86.4\% in the Group B; correct use of AED percentage was 93.5\% in the Group A and $92.4 \%$ in the Group B; the percentage of police officers that passed the questionnaire after the training was 63.2\% in the Group A and 69.8\% in the Group B (p 0.05).

Conclusion: The police officers that were trained by peer instructors showed comparable skills in BLSD for adult compared to those that were trained by professional instructors.
\end{abstract}

Keywords: Cardiac Arrest; Basic Life Support; Peer to Peer Education; Police Officers; Training

\section{Theory}

It has been widely demonstrated that bystanders' CPR improves survival rate of out of hospital cardiac arrest: for this reason, more bystanders should be trained to BLSD. To such extent BLSD training could be very challenging, especially if addressed at non medical population. Previous investigations in United States showed that police officers could be trained to use effectively AED and that police's AED programs are cost-effective [1,4]. In addi- tion, many studies demonstrated that police officers equipped with AED within large metropolitan cities achieved a decrease of callto-shock time provided by police officers as first responders and an increase in patient survival from out-of-hospital cardiac arrest $[5,15]$. Cardiac arrest is an important cause of death in the Italy. Although estimates of the annual number of sudden deaths due to out-of-hospital cardiac arrest vary widely, data from the Center for Disease Control and Prevention estimates that in the Italy approxi- 
Automated External Defibrillator Availability and CPR Training among Police Officers in the Campania Region: a Comparison of conventional and Peer-Led Trainings

03

\begin{tabular}{|l|c|c|c|c|c|c|c|}
\hline \multicolumn{1}{|c|}{ City or Region } & Time & Population & $\begin{array}{c}\text { CA in } \\
\text { public (\%) }\end{array}$ & $\begin{array}{c}\text { Schockable } \\
\text { Rhythm (\%) }\end{array}$ & $\begin{array}{c}\text { Bystanders } \\
\text { BLS (\%) }\end{array}$ & $\begin{array}{c}\text { ROSC } \\
\text { (\%) }\end{array}$ & $\begin{array}{c}\text { Survival } \\
\text { (\%) }\end{array}$ \\
\hline Torino (16) & $1992-1994$ & BW-OHCA & 14 & 32 & 28 & 18 & 9.7 \\
\hline Mestre (17) & $1996-1997$ & BW-OHCA & ND & 73 & 40 & 33 & 13 \\
\hline Piacenza (18) & $1999-2000$ & A-OHCA & 13 & 24 & ND & 13 & 11 \\
\hline Brescia (19) & $1997-2002$ & A-OHCA & 14 & 30 & 21 & 10 & 4.4 \\
\hline Forlì (20) & $1994-2005$ & BW-OHCA & 26 & 38 & ND & ND & 15 \\
\hline Friuli Venezia Giulia (21) & 1994 and & $\begin{array}{l}\text { Non-EMS } \\
\text { W-OHCA }\end{array}$ & 23 & 20 & 25 & 27 & 10.3 \\
& $2003-2004$ & & & & & \\
\hline Lombardia (22) & 2000 and 2003 & A-OHCA & 25 & 14 & 22 & 24 & 3.4 \\
\hline Cernusco sul Naviglio (23) & $2003-2004$ & S-OHCA & ND & 14 & 22 & 24 & 3.4 \\
\hline Bologna (24) & $2004-2007$ & AW-OHCA & 80 & 33 & 50 & 34 & 10 \\
\hline Sorrento (25) & $2007-2017$ & BW-OHCA & 36 & 31.1 & 16.7 & 22.4 & 8.6 \\
\hline
\end{tabular}

Table 1: The main italian studies from ' 90 that investigate the outcome of out-of-hospital cardiac arrest with PAD programs.

CA: cardiac arrest; BLS: basic life support; ROSC: return of spontaneus circulation; BW-OHCA: bystander witnessed out-of-hospital cardiac arrest; PAD: public access to defibrillation; A-OHCA: all out-of-hospital cardiac arrest; Non-EMS W-OHCA: non emergency medical service witnessed out-of-hospital cardiac arrest; S-OHCA: out-of-hospital cardiac arrest with shockable rhythms; AW-OHCA: all witnessed out-of-hospital cardiac arrest.

mately 60.000 people die annually before reaching a hospital or in emergency room [15]. In particular in Campania Region the annual number of sudden deaths due to out-of-hospital cardiac arrest was estimated approximately at 5.500 people. The main Italian studies from '90 on outcome of out-of-hospital cardiac arrest showed an improvement of survival by the rise of bystanders' CPR $[16,25]$ (Table 1).

\section{Hypothesis}

In this study we wanted to compare a peer to peer BLSD training to a professional BLSD training for police officers in the Campania region. Furthermore we matched in these two different trainings the skills maintained after one year.

\section{Methods}

In the years 2013-2018 in the Campania region we started a BLSD training program for police officers. We organized a total of 87 courses and compared peer to peer training to professional training on 1320 police officers (from 20 to 52 years old, 986 male and 334 female). The inclusion criteria were the willingness to participate to the study and informed consent was obtained. The police officers were divided in Group A (peer to peer training) and Group B (professional training). None of them were previously trained to BLSD, as confirmed by a questionnaire administered to the police officers before starting the course. In this questionnaire there were 20 questions about BLSD according to AHA and ILCOR Guidelines for CPR (2010) and to the AHA Guidelines update (2015) $[26,27]$ and it was based on PROCES study [28]. Each question had four possible answers and only one of them was correct. We gave 1 point for each correct question and 0 point for each wrong question: the test was passed giving 16 correct answers. The questions evaluated included: recognition of unconsciousness, initial evaluation, ratio of compressions/ventilations, characteristics of effective compressions, opening the airway and giving breaths, recognizing the phone number of Emergency Medical System (EMS), following the common steps of AED use (Appendix). The potential peerinstructors were recruited from senior police officers. Ten senior police officers attended a two-day BLSD instructor's course at the Federico II University according to the AHA instructors course. The instructors of the professional group were recruited from cardiologists and anesthesiologists or from AHA certified BLSD instructors. The course was structured according to AHA and ILCOR guidelines $[26,27]$ with video and skill training; at the end of the course we submitted to police officers the same questionnaire administered before starting the BLSD training. Then a final practical exam to assess the BLSD skills acquired by police officers was made by two blinded instructors. The skills evaluated were check for responsiveness, the calls to Emergency System 118, opening the airway and giving breaths (head tilt and chin lift, mouth to mouth breaths, mouth to mask breaths), chest compressions (correct hand posi- 
Automated External Defibrillator Availability and CPR Training among Police Officers in the Campania Region: a Comparison of conventional and Peer-Led Trainings

tion, adequate depth, correct rate, complete chest recoil) and correct ad safety use of AED (proper placement of the AED electrode pads, recall when to press the shock button, don't touch the victim while the AED is analyzing the heart rhythm or delivering a shock) (Table 2). BLS skills were measured with the Q-CPR using Resusci Anne manikin (Laerdal Medical -Stavanger, Norway). Furthermore we used AED Phylips HS1 trainer model. After one year we organized a refresh BLSD training and we evaluated the skills maintained in Group A and Group B with using the questionnaire and the practical exam.

\begin{tabular}{|l|l|}
\hline \multicolumn{1}{|c|}{ Check } & \multicolumn{1}{c|}{ Responsiveness or no movement } \\
\hline Call EMS & $\begin{array}{l}\text { Calls } 118 \\
\text { Get AED }\end{array}$ \\
\hline Open airway & $\begin{array}{l}\text { Head tilt-chin lift maneuver } \\
\text { Place ear near the victim's mouth and nose }\end{array}$ \\
\hline Giving breaths & $\begin{array}{l}\text { Mouth-to-mouth breaths (2 breaths -1 second } \\
\text { each) }\end{array}$ \\
\hline $\begin{array}{l}\text { Chest } \\
\text { compression }\end{array}$ & $\begin{array}{l}\text { Starts immediately } \\
\text { Correct hands position } \\
\text { Right compression frequency of 90-110 bpm } \\
\text { Right compression depth (5 cm) }\end{array}$ \\
$\begin{array}{l}\text { Complete chest recoil } \\
\text { Ensures continues effective chest compression } \\
\text { (No brake of more than 10 s) }\end{array}$ \\
$\begin{array}{l}\text { Proper placement of the AED electrode pads } \\
\text { Recall when to press the shock button } \\
\text { Don't touch the victim while the AED is analyz- } \\
\text { ing the heart rhythm or delivering a shock }\end{array}$ \\
$\begin{array}{l}\text { 20 points } \\
\text { AED }\end{array}$ \\
\hline
\end{tabular}

Table 2: BLSD skills evaluated.

\section{Statistical analysis}

The data were analyzed using a statistical software (SPSS for Windows, version 21, SPSS Inc, Chicago, IL). The results were expressed as mean+ SD or number of agents (\%) as appropriate. Unpaired t-test was used to compared the continuous variables between Group A and Group B. P values was two sided with P $\leq 0.05$ considered to be statistically significant.

\section{Results}

The data demonstrated that the two groups were comparable for age, height, weight, gender (Table 3). The results were expressed in percentage of skills properly executed. Check responsiveness percentage was $68.5 \%$ in Group A and 70.4\% in the Group $\mathrm{B}(\mathrm{ns})$; the percentage of calls to Emergency System 118 was $88.5 \%$ in the Group A and 90.9\% in the Group B (ns); open the airway and giving breaths percentage was $52 \%$ in the Group A and $52.3 \%$ in the Group B (ns); chest compressions percentage was $83.9 \%$ in the Group A and $86.4 \%$ in the Group B(ns); the percentage of correct AED use was $93.5 \%$ in the Group A and $92.4 \%$ in the Group B (ns) (Figure 1). While before the course the percentage of police officers that passed the questionnaire was $30 \%$ in both groups, after the training the percentage was $63.2 \%$ in the Group A and 69.8\% in the Group B (p 0.05) (Figure 1). After one year from the BLSD training course the results were similar in both group: in particular $70.9 \%$ in the Group A and 76.4\% in the Group B (ns) adequately performed the chest compressions (Figure 2), the percentage of correct AED use was $80.5 \%$ in the Group A and $81.4 \%$ in the Group B (ns) (Figure 3) and the percentage of police officers that passed the questionnaire was $69.2 \%$ in the Group A and $75.5 \%$ in the Group B (ns) (Figure 4).

\begin{tabular}{|c|c|c|c|}
\hline Characteristic value & Group A= 700 & Group B= 620 & p- \\
\hline Age yr (SD) & $38,8+9.8$ & $40.9+9.1$ & ns \\
\hline Height-cm (SD) & $165,5+8.8$ & $163+7.4$ & ns \\
\hline Weight-kg (SD) & $70.7+10.1$ & $73.7+9.8$ & ns \\
\hline Male Sex no (\%) & $535 / 700(76,4)$ & $451 / 620(72,7)$ & $n s$ \\
\hline
\end{tabular}

Table 3: Demographic data.

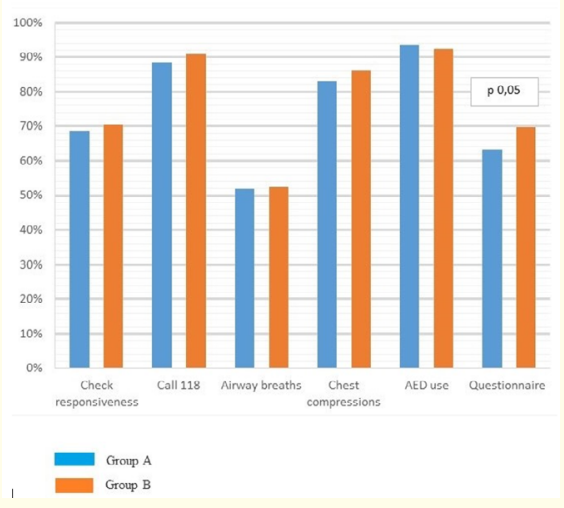

Figure 1: Percentage of skills properly executed after BLSD training. 


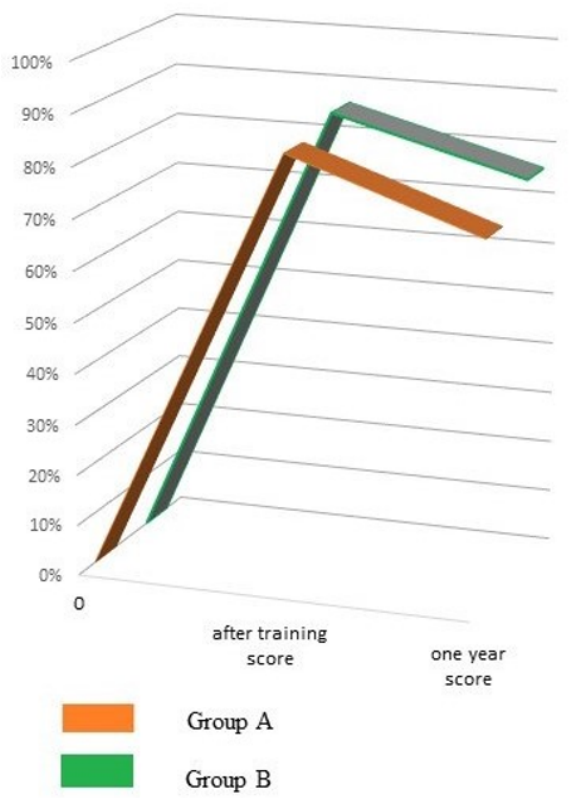

Figure 2: Chest compression.

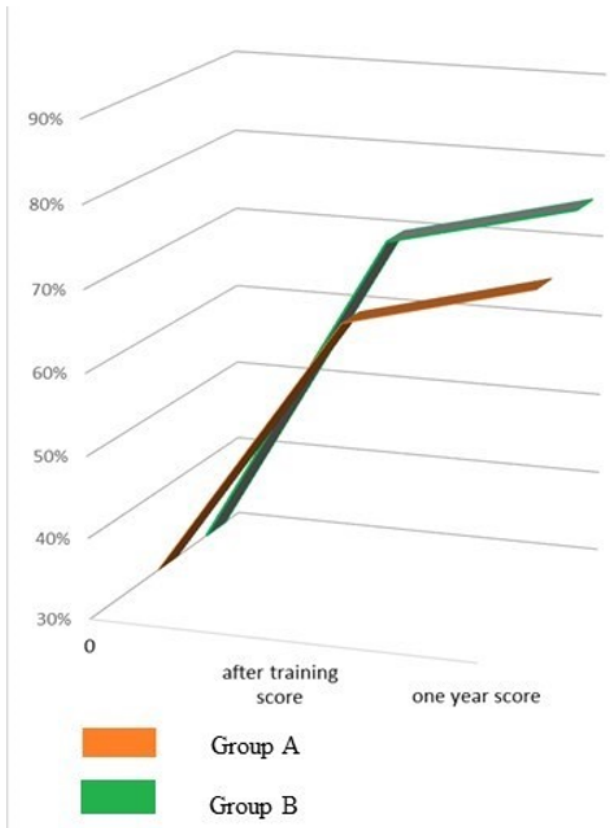

Figure 4: Questionnaire.

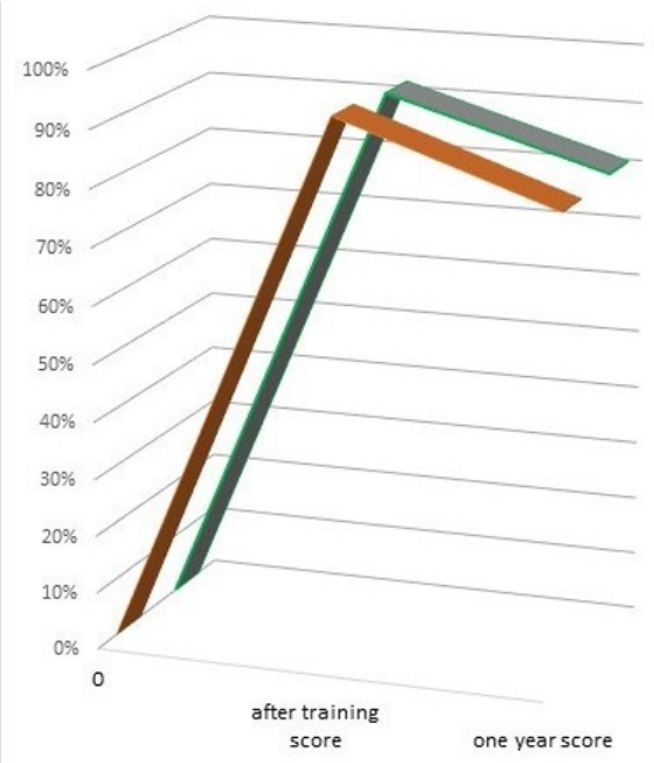

Group A

Group B

Figure 3: Correct AED use.

\section{Discussion}

Our study clearly showed that there were no difference in the quality of training between the two groups. The comparison between the groups for the single skill did not demonstrate any significant differences. But the only significant difference was how the course was perceived: police officers in Group A confirmed that they enjoyed the course and most of them would have to participate to the retraining course. In order to get the best and most effective compressions, the AHA and ILCOR recommends that the rescuers rotate every 2 minutes or at the end of every fifth CPR cycle [26]. At the 2015 Consensus Conference reached several conclusions about chest compressions and the of AHA and ILCOR 2015 new guidelines changed the steps of CPR from A-B-C (airway, breathing, circulation) to C-A-B (circulation, airway, breathing) [27]. The highest priority is to maintain circulation with high-quality chest compressions, then breathing and opening airway [29,31]. Furthermore compression-only (hand-only) CPR is recommended as the method of choice for the untrained rescuers because it is simpler to perform and it is easier to give instructions on the phone $[26,27]$. In adults with out-of-hospital cardiac arrest, compressiononly CPR performed by the bystanders has a higher success rate than standard CPR. In our study opening the airway and giving breaths percentage maneuvers were low in both group. The fail- 
Automated External Defibrillator Availability and CPR Training among Police Officers in the Campania Region: a Comparison of conventional and Peer-Led Trainings

ure to ventilate adequately is often caused by not maintaining an open airway. Regarding this maneuver Lester C., et al. [32] demonstrated with a questionnaire that the people expressed reluctance to resuscitate victims with unpleasant characteristics, like if vomit was present, if the casualty was dirty and if there was an unpleasant smell. Other deterrents mentioned were bleeding in or around the mouth, serious injuries, dangerous situation for the rescuer, HIV-positive status. In these situations the police officers can make compression-only CPR to alleviate the anxiety to perform ventilations. A key problem in learning and performing CPR is the loss of acquired knowledge over time. In fact in a study looking at the retention of CPR skills of successfully trained adults, after one year from the training course only $47 \%$ demonstrated correct hand placement on the manikin, $44 \%$ adequately performed the compressions depth and the compression rate was adequate in just $59 \%$ [30]. On the contrary another study demonstrated that in a group of secondary students the use of a song related to basic CPR was capable to reduce the loss of acquired theoretical knowledge compared to the traditional CPR training. Our study showed that after one year the BLSD skills were adequately performed whether by peer trained police officers or by professional trained police officers and the scores at the questionnaire were higher in both groups: this last finding probably was related to the refresh BLSD course. This result indicated the ability of peer instructor to teach effectively BLSD and that there were not necessary to organize a refresh course before one year from BLSD training. The recommendation for a defibrillation is one shock at a time for patients in a shockable rhythm. Today AEDs are easy to use and give clear and simple voice commands to guide the users. Furthermore police officers are not liable if someone die in Italy during a rescue. In fact first responders are immune from civil liability for any personal injury that results from act or omission in the use of the defibrillator in an emergency setting: they are protected under the license of the Medical Program Director, regional legislation, and the national Law [39].

\section{Conclusion}

This study demonstrated that a peer to peer BLSD training for police officers was feasible and could be as effective as a professional BLSD training. Peer education is an interesting concept for CPR training because it could improve the learning. Involving peers in the police officers' BLSD training could reduce the request of professional trainers. Police officers need to be convinced that aiding a victim in cardiac arrest is a worthwhile use of their time.
Early defibrillation makes a profound difference between life and death. It aligns with the Police mission to protect and serve.

\section{Conflict of Interest Statement}

No conflict of interest was declared by the authors.

\section{Financial Disclosure}

The authors declared that this study has not received financial support.

\section{Acknowledgements}

We are very grateful to the staff of Police Department of Naples for their excellent instruction and organization in particular Ornella Albanese, Silvana Basile, Marcello Damiano, Cosimo Donzelli, Mauro Storti and to all agents who took part in this study as tutors or as trainees.

\section{Appendix: Questionnaire}

1. It is important to starting CPR in safety conditions?

2. Can the rescuers move the victim?

3. For checking responsiveness, the rescuers must ask how the victim is?

4. For checking responsiveness, can the rescuers shaking carefully the victim?

5. How long the checking of circulation signs?

6. Where is the correct position of AED?

7. It is correct to do CPR during the analysis of the heart rhythm by AED?

8. What is the correct position of AED electrodes?

9. During the AED heart rhythm analysis, what is the correct position of the rescuer?

10. When it is possible to use AED?

11. When it is possible to deliver a shock?

12. How to check circulation signs?

13. How to check breathing?

14. It is correct to attach the AED to a conscious person?

15. How does a defibrillator work?

16. What are the benefits of using an AED during a SCA?

17. Can a heart stop beating after an AED has got it beating again?

18. It is possible to shock a victim accidentally?

19. Why it is wrong to wait the arrive of EMS before starting BLSD?

20. What requiring the maintenance of AED? 
Automated External Defibrillator Availability and CPR Training among Police Officers in the Campania Region: a Comparison of conventional and Peer-Led Trainings

\section{Bibliography}

1. Kooij FO., et al. "Training of police officers as first responders with an automated external defibrillator". Resuscitation 63.1 (2004): 33-41.

2. White RD., et al. "Evolution of a community-wide early defibrillation programme experience over 13 years using police/fire personnel and paramedics as responders". Resuscitation 65.3 (2005): 279-283.

3. Ross P., et al. "The use of AEDs by police officers in the City of London. Automated external defibrillators". Resuscitation 50.2 (2001): 141-146.

4. Hawkins SC., et al. "The role of law enforcement agencies in out-of-hospital emergency care". Resuscitation 72.3 (2007): 386-393.

5. Hirsch L M., et al. "Automated External Defibrillator Availability and CPR Training Among State Police Agencies in the United States". Annals of Emergency Medicine 60.1 (2012): 57-62.

6. Forrer CS., et al. "Estimated cost effectiveness of a police automated external defibrillator program in a suburban community: 7 yearsexperience". Resuscitation 52.1 (2002): 23-29.

7. Myerburg RJ., et al. "Impact of community-wide police car deployment of automated external defibrillators on survival from out-of-hospital cardiac arrest". Circulation 106.9 (2002): 1058-1064.

8. Papson K and Mosesso VN Jr. "Ten years of police defibrillation: program characteristics and personnel attitudes". Prehospital Emergency Care 9.2 (2005): 186-190.

9. Weisfeldt ML., et al. "Survival after application of automatic external defibrillators before arrival of the emergency medical system: evaluation in the resuscitation outcomes consortium population of 21 million". Journal of the American College of Cardiology 55.16 (2010): 1713-1720.

10. Joglar J A and Page R L. "Automated External Defibrillator Use by Police Responders. Where Do We Go From Here?". Circulation 106.9 (2002): 1030-1033.

11. Becker L., et al. "Eisenberg M Treatment of Cardiac Arrest with rapid Defibrillation by police in King County Washington". Preospital Emergency Care 18.1 (2014): 22-27.
12. Groh W., et al. "Limited Response to Cardiac Arrest by Police Equipped with Automated External Defibrillators: Lack of Survival Benefit in Suburban and Rural Indiana- The Police as Responder Automated Defibrillator Evaluation (PARADE)". Academic Emergency Medicine 8.4 (2001): 324-330.

13. Stein P., et al. "Impact of city police layperson education and equipment with automated external defibrillators on patient outcome after out of hospital cardiac arrest". Resuscitation 118 (2017): 27-34.

14. Husain S and Eisenberg M. "Police AED programs: a systematic review and meta-analysis". Resuscitation 84.9(2013): 11841191.

15. ISTAT Le principali cause di morte in Italia. Report 2012". Statistiche (2014): 1-18.

16. Casaccia M., et al. "Out-of-hospital cardiac arrest in an experimental model of the management of cardiologic emergencies in a metropolitan area". Giornale Italiano di Cardiologia 25.2 (1995): 127-137.

17. D'Este F., et al. "Extrahospital cardiac arrest: the experience of Mestre Emergency Service". Giornale Italiano di Cardiologia 28.6 (1998): 678-686.

18. Capucci A., et al. "Tripling survival from sudden cardiac arrest via early defibrillation without traditional education in cardiopulmonary resuscitation". Circulation 106.9 (2002): 10651070.

19. Cappato R., et al. "Prospective assessment of integrating the existing emergency medical system with automated external defibrillators fully operated by volunteers and lay persons for out-of-hospital cardiac arrest: the Brescia Early Defibrillation Study (BEDS)". European Heart Journal 27.5 (2006): 553-561.

20. Fabbri A., et al. "Monitoring intervention programmes for outof-hospital cardiac arrest in a mixed urban and rural setting". Resuscitation 71.2 (2006): 180-187.

21. Kette F., et al. "Increased survival despite a reduction in out-ofhospital ventricular fibrillation in north-east Italy". Resuscitation 72.1 (2007): 52-58.

22. Citerio G., et al. "Prospective performance evaluation of emergency medical services for cardiac arrest in Lombardia: Is something moving forward?". European Journal of Emergency Medicine 13.4 (2006): 192-196. 
23. Terranova P., et al. "Early outcomes of out-ofhospital cardiac arrest after defibrillation: A 24 months retrospective analysis". Indian Pacing and Electrophysiology Journal 6.4 (2006): 194-201.

24. Taglieri N., et al. "Impact of a territorial ST-segment elevation myocardial infarction network on prognosis of patients with out-of hospital cardiac arrest". Acute Cardiac Care 13.3 (2011): 143-147.

25. Santomauro M., et al. "Survival of Out-of-Hospital Cardiac Arrest by Early Defibrillation in the Sorrento Peninsula". Annals of Heart 4 (2019): 68-73.

26. Bhanji F., et al. "Part 16: education, implementation, and teams: 2010 American Heart Association Guidelines for Cardiopulmonary Resuscitation and Emergency Cardiovascular Care". Circulation 122.18-3 (2010): S920-S933.

27. Neumar R.W., et al. "Executive Summary:2015 American Heart Association Guidelines Update for Cardiopulmonary Resuscitation and Emergency". Cardiovascular Care Circulation132.18-2 (2015): S315-S367.

28. Sayre MR., et al. "Hands-Only (Compression-Only) Cardiopulmonary Resuscitation: A Call to Action for Bystander Response to Adults Who Experience Out-of-Hospital Sudden Cardiac Arrest". Circulation 117.16 (2008): 2162-2167.

29. Cho Y., et al. "The effect of peer-group size on the delivery of feedback in basic life support refresher training: a cluster randomized controlled trial". BMC Medical Education 16 (2016): 167-174.

30. Smith A., et al. "Trials of teaching methods in basic life support (4): comparison of simulated CPR performance at unannounced home testing after conventional or staged training". Resuscitation 61.1 (2004): 41-47.

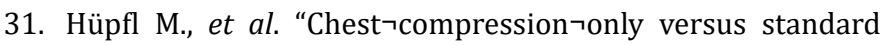
cardiopulmonary resuscitation: a meta-analysis". Lancet 376.9752 (2010): 1552-1557.

32. Lester C., et al. "Teaching schoolchildren cardiopulmonary resuscitation”. Resuscitation 31.1 (1996): 33-38.

33. Cabrini L., et al. "Bystander 7 initiated chest compressiononly CPR is better than standard CPR in out of hospital cardiac arrest". HSR Proc Intensive Care Cardiovasc Anesth 2.4 (2010): 279-285.
34. Fujiwara T., et al. "Comparison of peer-led versus professionalled training in basic life support for medical students". Advances in Medical Education and Practice 2 (2011): 187-191.

35. Santomauro M., et al. "Future perspective in BLSD training: The importance of peer-to peer education in high school students". Journal of translational science 4 (2018): 1-6.

36. Toner P., et al. "Teaching basic life support to school children using medical students and teachers in a 'peer-training' model - results of the 'ABC for life' programme”. Resuscitation 75.1 (2007):169-175.

37. Hughes TC., et al. "Advanced Cardiac Resuscitation Evaluation (ACRE): a randomized single-blind controlled trial of peer-led vs expert-led advanced resuscitation training". Scandinavian Journal of Trauma, Resuscitation and Emergency Medicine 18 (2010): 3-10.

38. Basanta Camiño S., et al. "Assessment of knowledge and skills in using an Automated External Defibrillator (AED) by university students A quasi-experimental study". Medicina Intensiva 41.5 (2017): 270-276.

39. Legge 3 aprile 2001, n. 120 "Utilizzo dei defibrillatori semiautomatici in ambiente extraospedaliero". Gazzetta Ufficiale n. 88 del 14 aprile (2001).

\section{Volume 3 Issue 8 August 2019}

(C) All rights are reserved by Maurizio Santomauro., et al. 